\title{
A Case Study of Transient and Dynamic Performance of Saturated Core Reactor Static Var Compensator
}

\author{
J.A.F. Barbosa $\mathrm{Jr}^{1}$, J. C. Oliveira ${ }^{1}$, A. B. Vasconcellos ${ }^{2}$ and J. M. Pacheco ${ }^{2}$ \\ ${ }^{1}$ Faculty of Electrical Engineering \\ UFU, Federal University of Uberlândia \\ Campus Santa Mônica - Av. João Naves de Ávila, 2121- Bloco 3N - Uberlândia (Brazil) \\ Phone/Fax number:+55 34 32394733/+55 34 32394704, e-mail: johnareis@gmail.com, jcoliveira@ufu.br \\ ${ }^{2}$ Department of Electrical Engineering, Federal University of Mato Grosso \\ Av. Fernando Corrêa da Costa, Coxipó - Cuiabá (Brazil) \\ Phone number: +55 65 36158784, e-mail: arnulfo@ufmt.br, jackson@ufmt.br
}

\begin{abstract}
This paper presents results related to transient, dynamic and steady state response of a Saturated Core Reactor Static VAr Compensator (SCR-SVC) at regulating a real radial $230 \mathrm{kV}$ transmission line supplying a low density and highly distributed load in a developing area of Brazil. The studies are carried out using a time domain computational simulator in which a comprehensive model for a given twin-triple saturated reactor compensator model was implemented to cope with the receiving end load requirements for voltage regulation. Investigations are then performed to highlight the overall system and reactive compensator behavior at the occurrence of the reactor switch on conditions, final load relief and harmonic distortions.
\end{abstract}

\section{Key words}

Static Var Compensator, Saturated Reactor, Voltage Control, Magnetic Core, Power Quality.

\section{Introduction}

Over the world it is recognized that a large number of radial transmission lines feeding relatively small loads at their end may show voltage problems, being the regulation an important matter to deal with. This is particularly relevant when large territorial extension, energy consumption concentration in specific regions and predominant hydroelectric generation are considered. If this condition occurs and the transmission system operates with variable load conditions, the receiving end terminals may show both voltage increase and decrease with the load and this may exceed acceptable values. Searching for the conformity of the voltage standards, the most traditional solutions find sustentation in the process of reactive compensation. Amongst the mechanisms used to achieve this goal stands out the use of reactive compensators. These devices have in common the characteristic of providing dynamic reactive power injection or consumption in accordance with system requirements.
Within the above context, the thyristor controlled reactors with a parallel capacitor bank have been widely used. This technology, which appeared in the 1980's, is still highly attractive for many applications. Although the recognized advantages offered by these products, it must be stressed they are based on electronic control technology and this principle, for some application, may be show same disadvantages in relation to cost of investment as well as maintenance. Thus, when simpler solutions requiring lower cost, less maintenance care are required, other technologies may arise as solutions offering a compromise between regulation effectiveness and equipment costs. This is the case of the so called Saturated Reactor Static Compensator. Such equipment is not new and it was utilized for decades when the technology of semiconductors was still embryonic [1], [2], [3]. However, its use did not become a widespread solution, mainly due to the technical properties offered by the electronic technology as well as the manufactures preference for more updated and advanced resources.

Even so the saturated reactors compensators belong to the old fashion solutions, for some specific application, the idea of recuperating such product may represent a balance between system operational performance requirements and investment. In fact, the mentioned attractive features of such equipment, such as: competitive cost, operational simplicity, low maintenance requirement and the ability to promote the voltage control based on the intrinsic operative property of the equipment have motivated some researchers to carry on with this subject [3].

The saturated core reactor compensator is basically given by a suitable combination of a magnetic device built up using commercial magnetic material and special arranged windings and fixed parallel capacitor [1], [2], [3], [4]. This yields to robust equipment, with reduced maintenance, relative good efficiency in the voltage 
regulation and a short response time. Such advantages, added to the low cost in comparison to the electronic alternatives, become these devices attractive for use in electrical systems. Going back to the basic principles, the non-linearity of the curve $\mathrm{BxH}$ of the magnetic core defines one of the most important operating properties of the device. Due to this fact, this technology will produce harmonic currents to be injected in the supply busbar. This subject has been discussed in [3], [5], [6], [7], [8] and will not be further considered in this paper.

By describing the equipment throughout the time domain program facilities the focused compensator was implemented and studies were carried out using a real $230 \mathrm{kV}$ system data. This electrical arrangement represents a classical situation found in a growing area of great development fed by a long radial line. Using this practical example, load variations and voltage investigation at the receiving end were performed to highlight the compensator effectiveness at attending the legislation concerning voltage regulation. The results are then shown and discussed to enhance the transient and dynamic behavior of the overall electrical complex at the occurrence of equipment inrush and sudden load reduction.

\section{Saturated Reactor Static Compensator arrangement}

The saturated reactor static compensator basic principle can be seen throughout Fig. 1. It shows the existence of two main components. The saturated reactor has the function of absorbing variable reactive power in accordance with its saturation level and the fixed parallel capacitor. The later will produce the reactive power to be injected as a function of the supply voltage. Thus, the net value of reactive power as seen from the busbar will be given in accordance with the operating conditions imposed by the network upon the compensator. Further details about the overall structure can be found in [3].

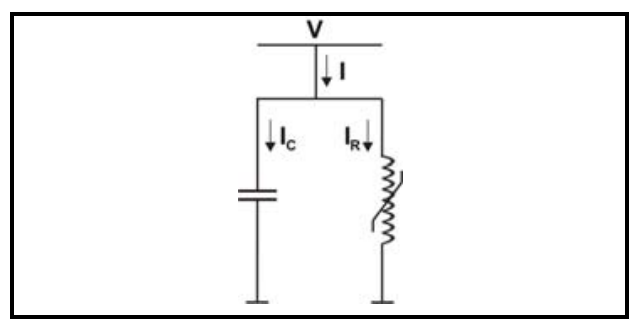

Fig. 1. The basic physical conception for the reactive compensator.

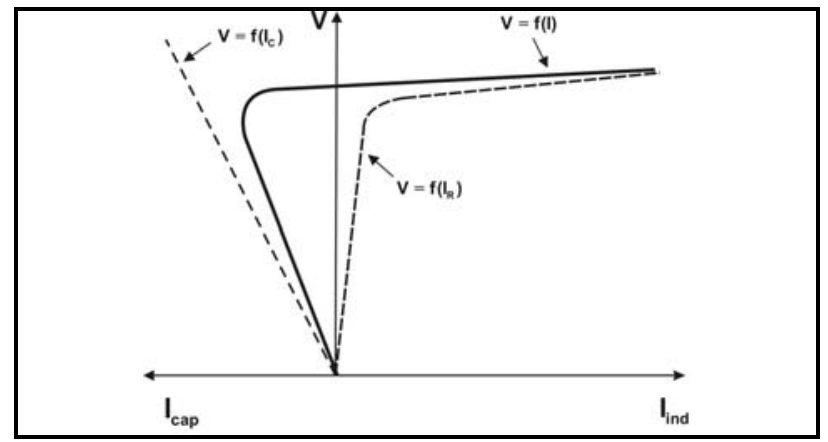

Fig. 2. The VxI characteristic for the saturated core reactor compensator.
The final V versus I characteristic for the equipment is illustrated in Fig. 2. It is possible to notice that there will be an operating point that indicates the inductive power totally compensated by the capacitive one. This corresponds to zero value for the net current. On the left side the equipment will produce a net capacitive power and on the right the reactor will dominate the process. This implies that the device behavior as far as the production of reactive power is concerned will be linked to the busbar voltage. In addition, the VxI characteristic revels that the voltage regulation will depend upon the slop defined by the non-linear $\mathrm{BxH}$ relationship.

As far as the harmonic compensation strategy is concerned, the use of special arrangements for the windings provides means for the so called internal compensation. This is provided by the "twin-tripler" (six magnetic columns) or the "treble-tripler" (nine magnetic columns) structures [3]. In this way, Fig. 3 illustrates the first arrangement. This is made up by two sets of three phase magnetic structures with a phase-shift of $30^{\circ}$. Using this methodology only the harmonic currents defined by the expression $n=12 k \pm 1$ will be injected in the supply.

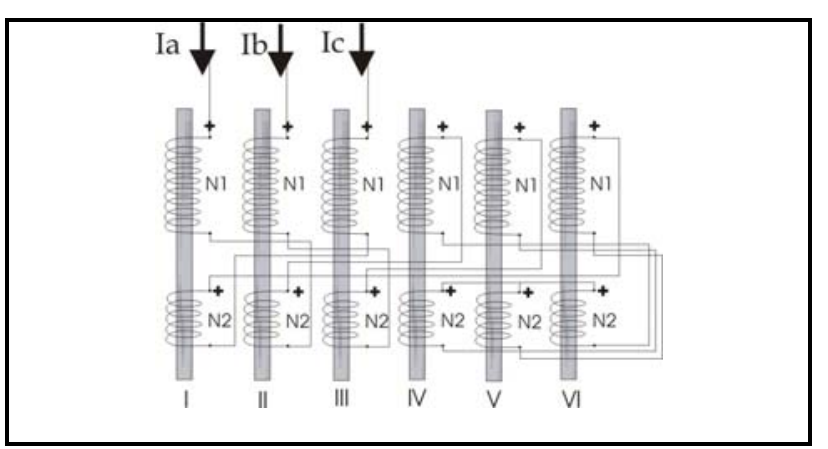

Fig. 3. The twin-tripler constructive arrangement for the saturated reactor.

\section{Computational Studies}

Fig. 4 gives the radial system that was selected to this paper studies. As it can be noticed, relatively small loads are supplied along the line extension and, at its end, the largest consumer is fed. Due to the voltage variation that may occur during operation, a static reactive compensator using saturated reactor has been allocated to provide the required voltage regulation.

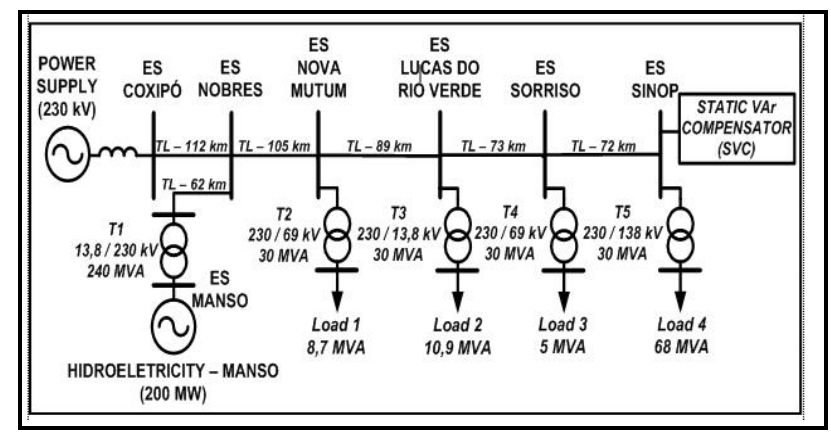

Fig. 4 - Single-line diagram for the electrical system. 
The results selected to be given and discussed in this paper are related to two situations. One refers to the occurrence of a sudden load reduction of about $70 \%$ of the original value and the other to the equipment energization. Therefore, the first investigation aims at showing the dynamic response offered by the compensation equipment and the second focuses the transient behavior. The only voltage to be given and discussed in this paper is the $230 \mathrm{kV}$ receiving end busbar at the Sinop location and the saturated reactor current. To accomplish with the necessary voltage regulation the compensator was selected with a saturated reactor of 25 MVAR with a parallel capacitor of 15 MVAr. Due to the lack of space the other data related to the electrical system was not inserted in this paper, however, they may be found in [9].

\section{A. Abrupt load reduction with no SCR-SVC}

This situation corresponds to the system behavior provoked by a sudden load reduction of $70 \%$ at the final consumer with no static compensator inserted. Priory to the load change the rms voltage was found to be 217.6 $\mathrm{kV}$. This value is $5.4 \%$ lower than the rated voltage. This implies that the system, in its original situation, does not accomplish the standard requirements. At $\mathrm{t}=1 \mathrm{~s}$ the load reduction occurs and a consequent voltage increase of $6.89 \%$ in relation to the rated voltage is found at the 230 $\mathrm{kV}$ SINOP busbar. This phenomenon was programmed to last for $0.5 \mathrm{~s}$ and all over this period the voltage rms value went up to $245.7 \mathrm{kV}$. The instantaneous voltage behavior previously to the load relief, during this event and after the load restoration is illustrated in Fig. 5.

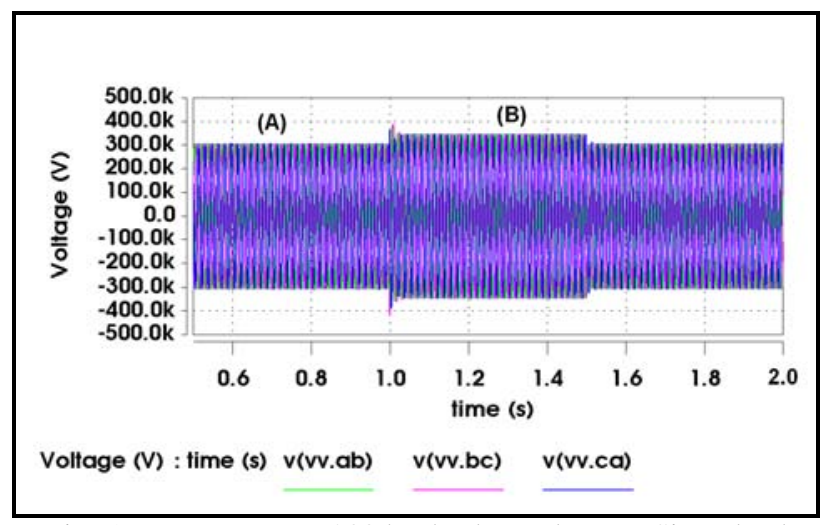

Fig. 5 - Instantaneous $230 \mathrm{kV}$ busbar voltage at Sinop load without compensator insertion.

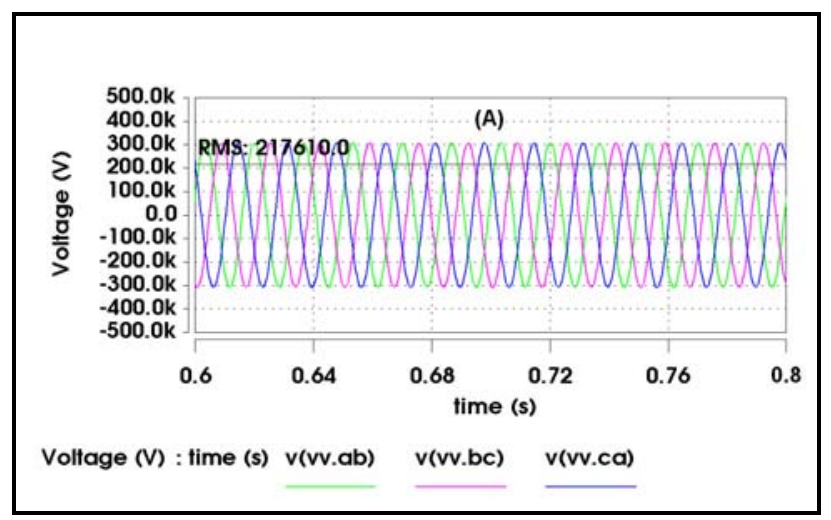

Fig. 6 - Instantaneous $230 \mathrm{kV}$ busbar voltage at Sinop load without compensator insertion - Region A.
In order to provide better information about specific periods Figs. 6 and 7 provide zoom to the regions A (original loading) and B (load relief). The results are clear enough to demonstrate that the $230 \mathrm{kV}$ busbar voltages do not attend the standard demands in both situations, i.e. before the load reduction and during this event.

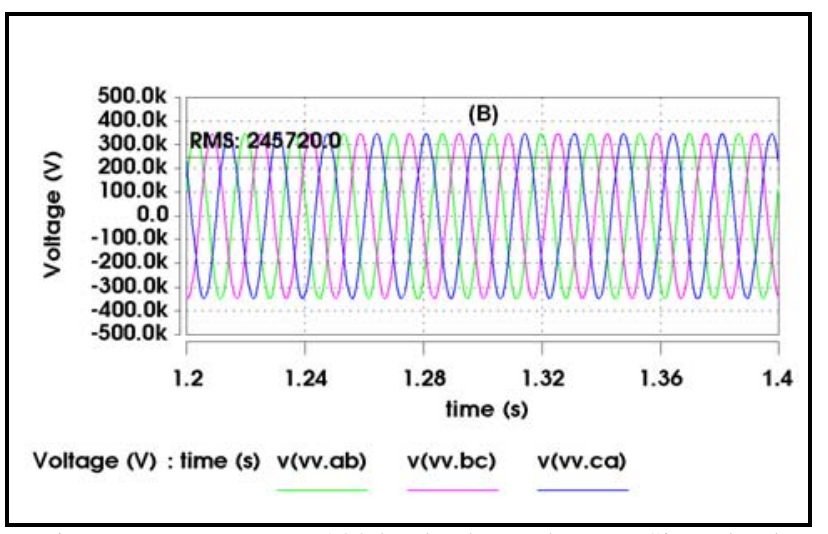

Fig. 7 - Instantaneous $230 \mathrm{kV}$ busbar voltage at Sinop load without compensator insertion - Region B.

\section{B. Abrupt load reduction with SCR-SVC insertion}

The same previous operation was repeated with a 25 MVAr saturated core reactor and a 15 MVAr fixed capacitor bank forming the SCR-SVC. The physical location where the compensator was installed can be seen in Fig. 4. This corresponds to the receiving $230 \mathrm{kV}$ end of the radial transmission line (Sinop busbar). Fig. 8 shows the new time domain voltage waveform over the period of study (between 0.4 and 2.0s).

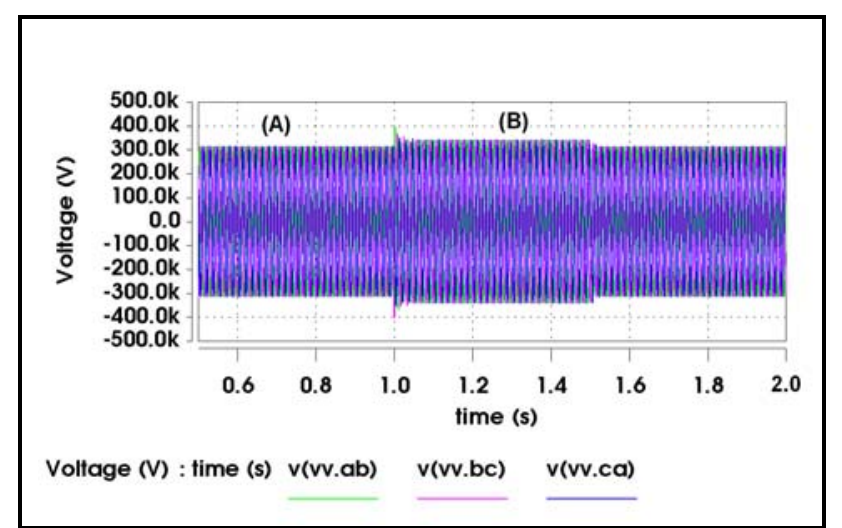

Fig. 8 - Instantaneous $230 \mathrm{kV}$ busbar voltage at Sinop load with compensator insertion.

The effectiveness of the static compensator in maintaining the voltage at Sinop $230 \mathrm{kV}$ busbar within the rms voltage limits defined by the standards can be easily seen throughout the region A and B zooms, as given by Figs. 9 and 10. Before the load reduction the voltage is $222.4 \mathrm{kV}$ which is $3.3 \%$ below the rated voltage. During the event the voltage level has raised to $238 \mathrm{kV}$, i.e. $3.48 \%$ above of the rated voltage. After $\mathrm{t} \geq 1$. 5 s the voltage comes back to $222.4 \mathrm{kV}$. To provide the necessary compensation performance, the saturated reactor acts in such a way to absorb reactive power from the electrical system. 


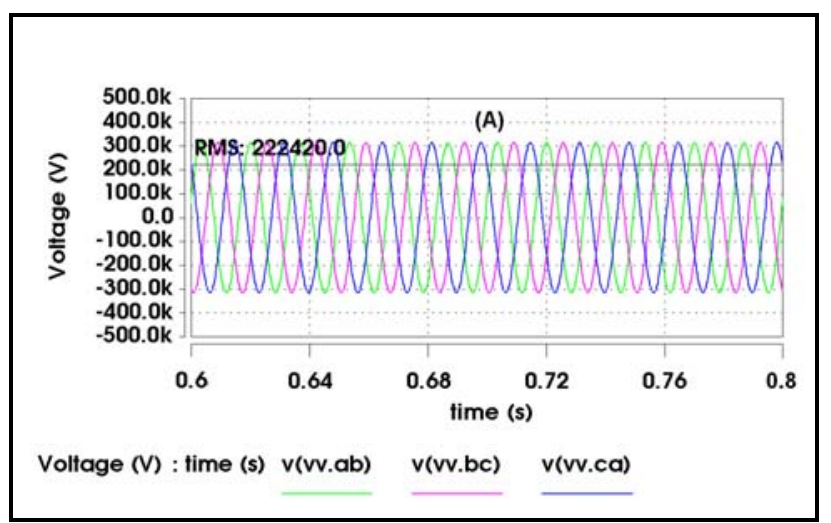

Fig. 9 - Instantaneous $230 \mathrm{kV}$ bus bar voltage at Sinop load with compensator insertion - Region A.

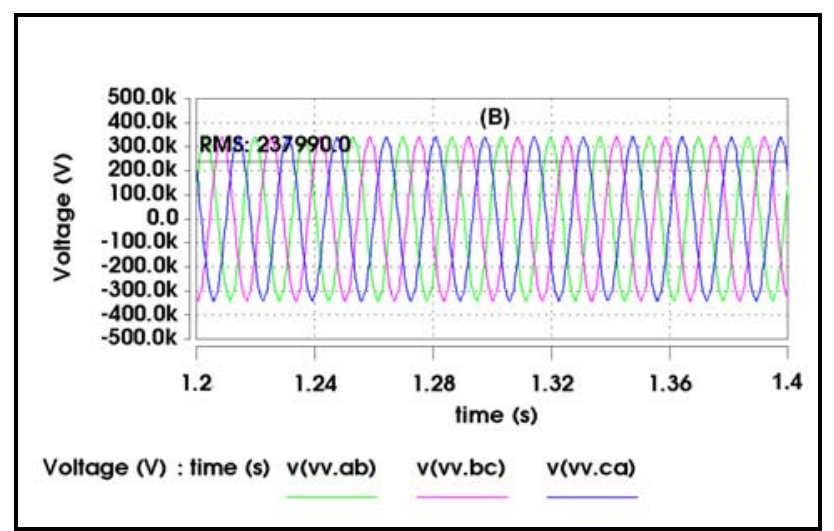

Fig. 10 - Instantaneous 230 kV busbar voltage at Sinop load with compensator insertion - Region B.

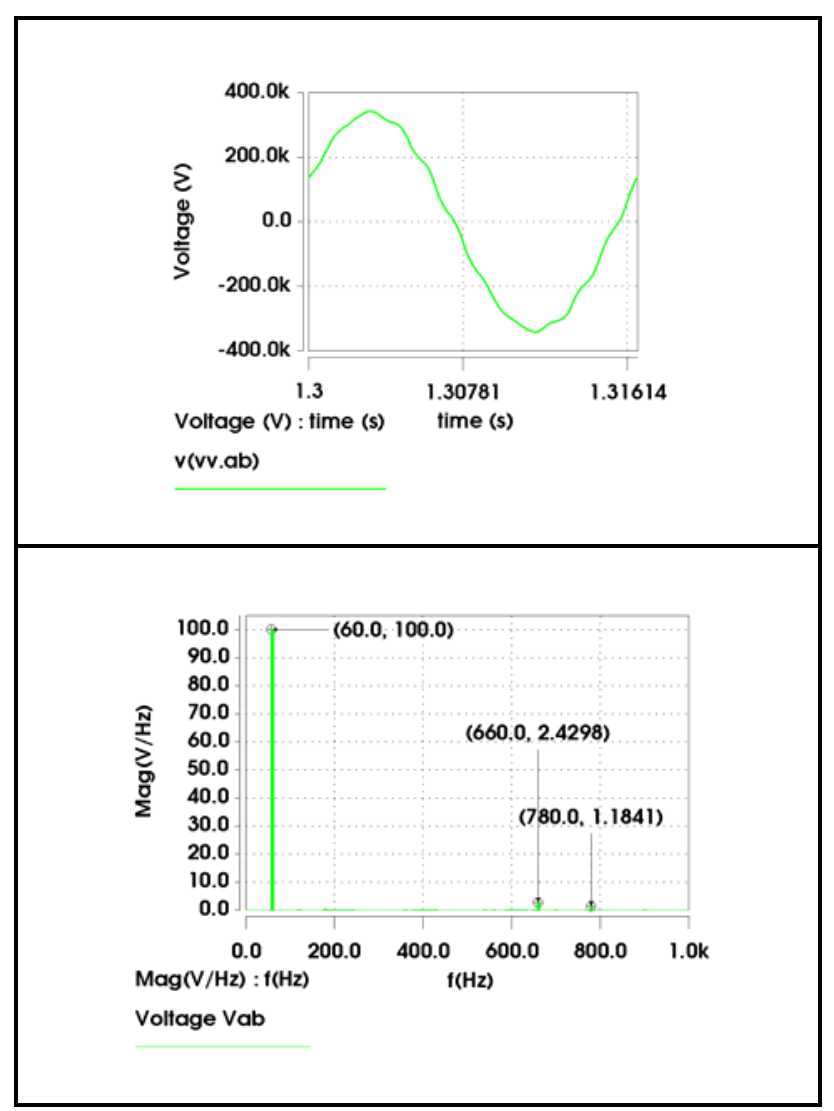

Fig. 11 - Phase to phase AB voltage waveform and corresponding harmonic spectrum with the saturated reactor compensator.
By recognizing the fact that the saturated reactor generates harmonic currents having the same order as a 12 pulse rectifier, the busbar voltage waveform is further considered, as shown in Fig. 11. Both the steady state voltage waveform and the corresponding harmonic spectrum are given. The THD found at the $230 \mathrm{kV}$ busbar is around $2.7 \%$ and the individual components are in agreement with the expected frequencies.

\section{Transient caused by the compensator inrush}

It is well known that transformers and capacitors cause high transients at their energization and disconnection from the mains. As the saturated reactor compensator combines an electromagnetic device with a capacitor bank, the transient behavior involving the equipment operation under this situation must be deeply investigate to prevent possible operational impacts upon the overall system. In this way, Fig. 12 illustrates the individual inrush associated to the reactor connection and later the capacitor entrance in operation. At $t=0,5 \mathrm{~s}$ occurs the saturated reactor insertion and 1s counted from this moment, the capacitor is switched on. Therefore, the static compensator insertion was split in two stages with the objective of attenuating the transient phenomenon.

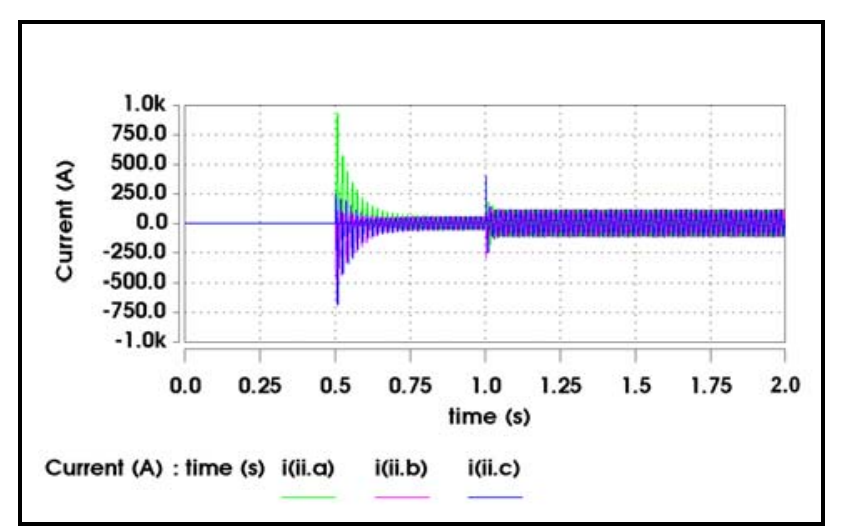

Fig. 12 - Saturated reactor inrush phenomenon.

Just to provide means for a better visualization of the first transient phenomenon, related to the reactor switch on, Fig. 13 illustrates the zoom of this region.

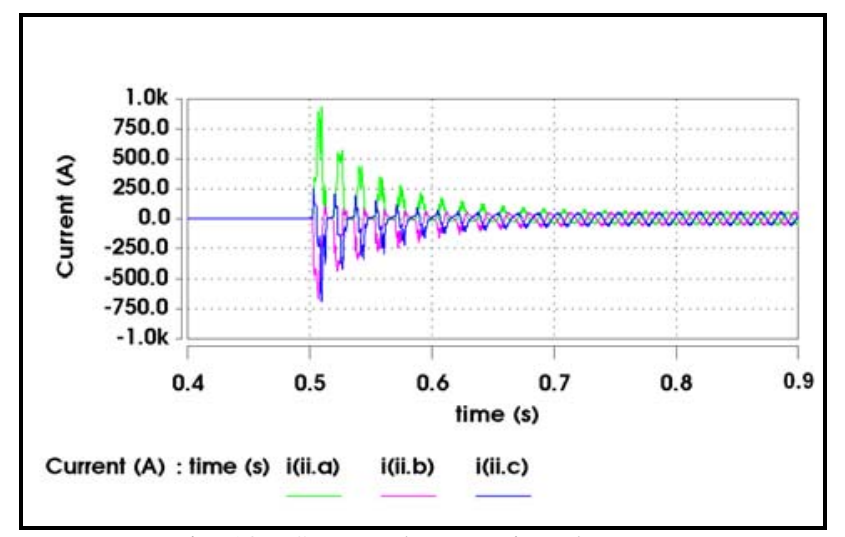

Fig. 13 - Saturated reactor inrush zoom. 
The results show that the maximum peak found for the transient current at the reactor connection is related to the line A. This value reached 933A which is about 10.5 times the equipment rated current. The reactor reached its steady state condition in about 10 cycles. Once the capacitor is connected, a new peak current can be detected. This highest level occurred to line $\mathrm{C}$ which shows a peak value of 402A. This is in total agreement with conventional capacitor inrush phenomenon. The capacitor steady state is reached very rapidly as often happens with this type of component. From this moment onwards the static compensator is completely connected to the Sinop busbar.

The Fig 14 shows the transient currents supplied to the parallel capacitor unit. The overall phenomenon is quite classical and is in accordance with expected typical capacitor inrush waveforms.

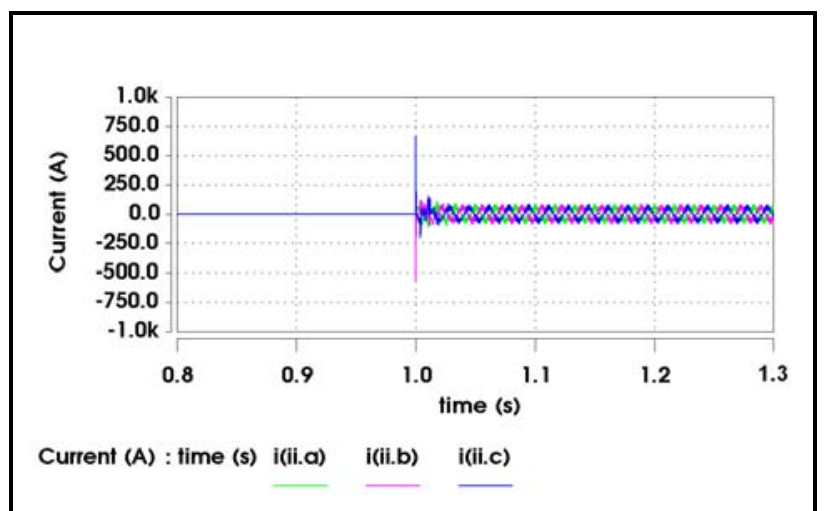

Fig. 14 - Transient inrush current at the capacitor switch on phenomenon.

\section{Saturated reactor steady state current waveform}

The saturated reactor current waveform associated to the e static compensator action due to the abrupt load relief is given in Fig. 15. Both regions $\mathrm{A}$ and $\mathrm{B}$ are shown. The first corresponds to the operation with the original load and the second one to the partial load rejection condition. The later situation produces the reactor operation so that the device drives 25 MVAr of reactive power. The large current increase clearly emphasize the equipment saturation and the new level reached by the current. This is close agreement with expected physical behavior.

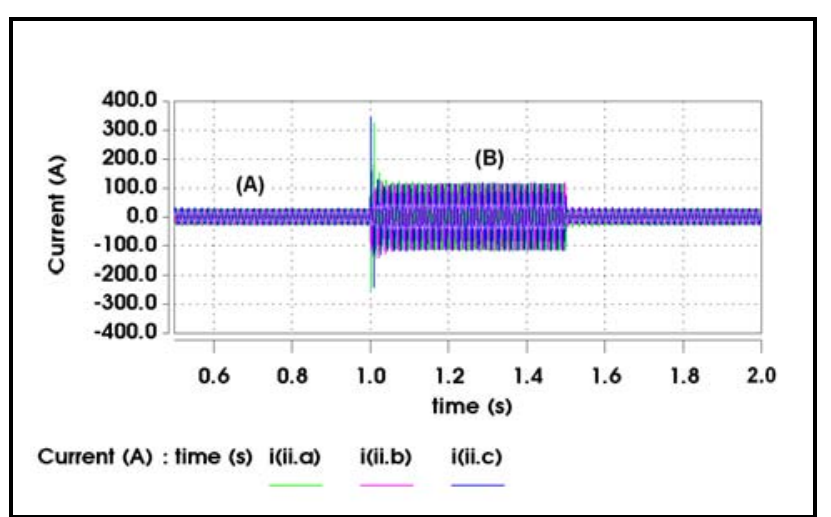

Fig. 15 - Current waveform associated to the saturated reactor unit with normal and reduced load conditions.
As far as region A (original load) is concerned, Fig. 16 provides a clearer view of the reactor current. It can be seen that the rms value is around 19.2A. This is roughly $30 \%$ of the reactor rated current. The waveform reveals the expected distortion linked to the twin-tripler arrangement. The figure scale was chosen so as to provide comparative terms with the next one.

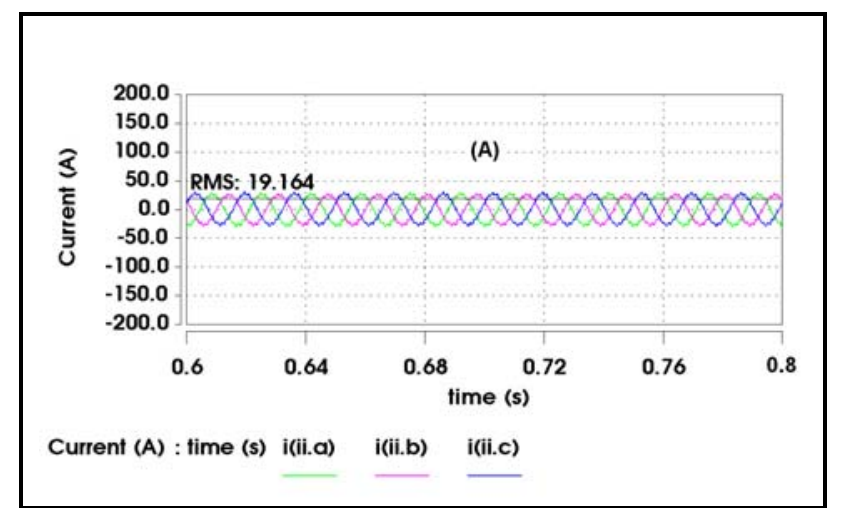

Fig. 16 - Reactor current waveform zoom during original load condition at Sinop.

In a complementary way, Fig. 17 details the current waveforms related to the saturated reactor during the operation with Sinop load reduction of about $70 \%$. The presence of the saturated reactor has kept the voltage within standard limits and to achieve this goal its current has gone up to 61.6A. i.e. $98 \%$ of the corresponding rated current.

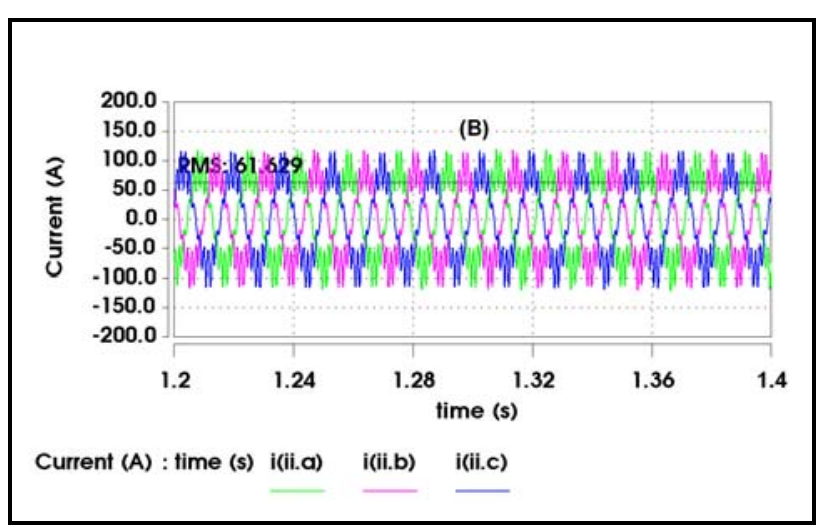

Fig. 17 - Reactor current waveform zoom during reduced load condition at Sinop.

The above result is quite clear in showing the highly distorted current waveform. The general aspect is in close agreement with the expected shape. Aiming at providing a more comprehensive view of the distortions, Fig. 18, give details about the harmonic composition.

The current THD has reached roughly $27.5 \%$ with the $11^{\text {th }}$ and $13^{\text {th }}$ components being the most relevant ones. This is in close agreement with expected values and orders as the Twin-Tripler reactor arrangement has been utilized. The results related to the harmonic orders are in accordance with the general expression $12 \mathrm{k} \pm 1$. 


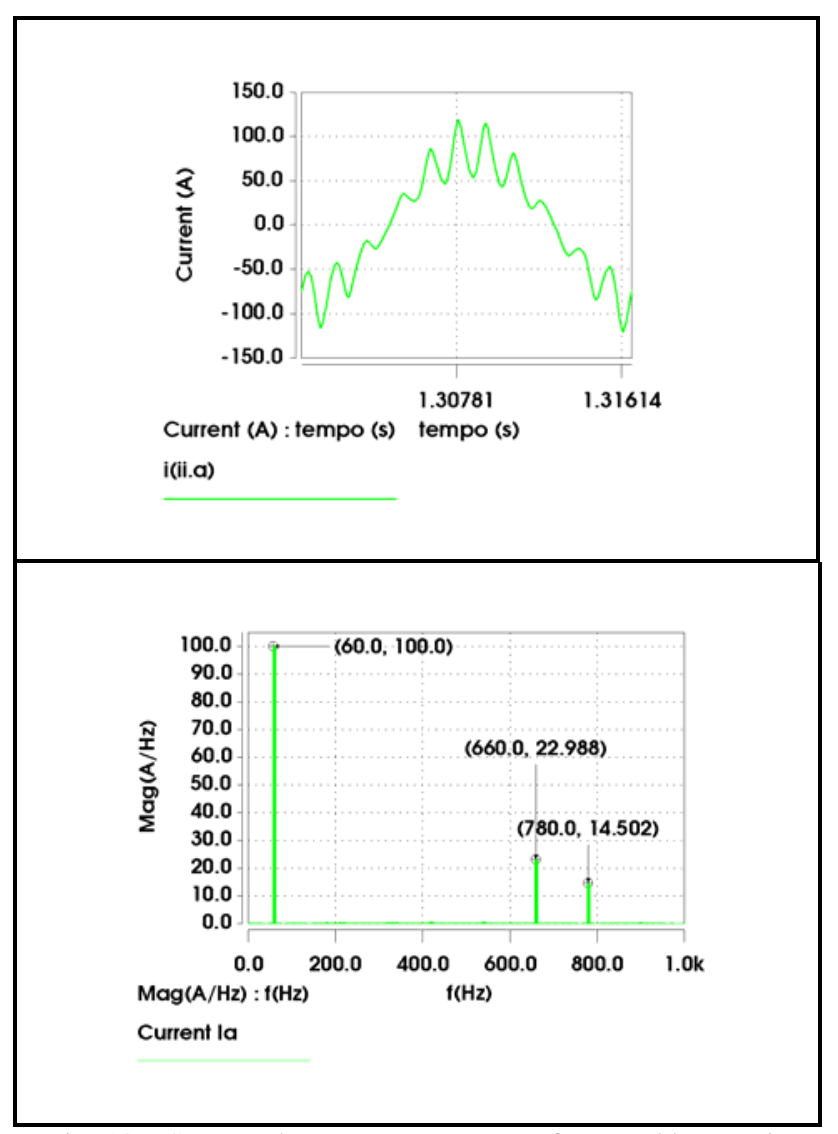

Fig. 18 - Saturated reactor current waveform and harmonic spectrum during reduced load operation at Sinop.

\section{Conclusions}

This paper has focused an old fashion type of compensator which has been considered for specific situations where the voltage regulation requirements are not so strict. By modeling the device in a time domain program it was possible to estimate the transient, dynamic and steady state performance of the overall arrangement. To enhance the program potentiality and the static compensator effectiveness in regulating the voltage level, an abrupt load variation was considered to the investigations. In addition to the operational advantages associated to the use of saturated reactors, it has been shown that it has drawbacks such as harmonic distortion and inrush phenomenon.
These aspects reveal that side effects should not be forgotten and they point out to the need of complete studies before the solution is implemented in real schemes. Although the results have shown that the use of the focused reactive compensator is quite effective, it must be stressed that the general behavior here describe are linked to the given application and the good general performance can not be readily extended to other configurations. In fact, the transient, dynamic and steady state performances must be carefully investigated before real utilization VAr or any other technique to voltage regulation.

\section{References}

[1] E. Friedlander, K. M. Jones "Saturated reactors for Long Distance Bulk Power Lines”, Electrical Review, pp 940 943, 27th June 1969.

[2] Cooper, C. B., and Young, D. J., "Saturated Reactor and Compensator for Stabilizing Voltage at Load and Generation Points”, IEE International Conference on HD and/or AC Power Transmission, November 1973, London.

[3] A. B. VASCONCELLOS, "Modeling, design and construction of saturated core reactor static compensator focusing power quality requirements" - $\mathrm{PhD}$ thesis Federal University of Uberlandia - Brazil - 2004.

[4] M. A. Carvalho, "Application of Saturated Reactors in Systems of Transmission”, in Proc. XIII SNPTEE, Camboriú-SC, Brazil, October 1995.

[5] J. C. Oliveira, A. B. Vasconcellos, R. Apolônio, "Saturated Core Reactor Static Compensator: Computational Versus Experimental Performance Analysis”, in Proc. XI ICHQP, New York-NY, USA, September 2004.

[6] J. C. Oliveira, A. B. Vasconcellos, R. Apolônio, "A Strategy for Voltage Regulation in Eolic Systems”, in Proc. XI ICHQP, New York-NY, USA, September 2004.

[7] J. C. Oliveira, A. B. Vasconcellos, R. Apolônio; "Saturated Core Reactor Static Compensator: Harmonic Generation under Ideal and No Ideal Conditions of Supply”; V SBQEE, Aracaju-SE, Brazil, August 2003.

[8] J. C. Oliveira, A. B. Vasconcellos, R. Apolônio; “Analysis of Dynamic Performance of a Saturated Core Reactor Static Compensator" (in Portuguese), VI SBQEE, BelémPA, Brazil, v. II. p. 356-361, August 2005.

[9] J. A. F. BARBOSA Jr., "Transient and Dynamic Power System Studies with Saturated Core Reactor Static Compensators” - MSc dissertation - Federal University of Uberlandia - Brazil - 2008. 